\title{
Leaching behaviour of and Cs disposition in a UMo powellite glass-ceramic
}

\author{
E.R. Vance ${ }^{\mathrm{a}, *}$, J. Davis $^{\text {a }}$, K. Olufson ${ }^{\text {a }}$, D.J. Gregg ${ }^{a}$, M.G. Blackford ${ }^{\text {a }}$, G.R. Griffiths ${ }^{\text {a }}$, \\ I. Farnan ${ }^{\text {b }}$, J. Sullivan ${ }^{\text {c}}$, D. Sprouster ${ }^{\text {c }}$, C. Campbell ${ }^{\text {c }}$, J. Hughes ${ }^{\mathrm{c}}$ \\ a Institute of Materials Engineering, ANSTO, Kirrawee DC, NSW 2232, Australia \\ ${ }^{\mathrm{b}}$ Department of Earth Sciences, University of Cambridge, Cambridge CB2 3EQ United Kingdom \\ ${ }^{\mathrm{c}}$ Centre for Antimatter-Matter Studies (CAMS), Research School of Physics and Engineering, Australian National University, Canberra, ACT 0200, Australia
}

\section{A R T I C L E I N F O}

\section{Article history:}

Received 19 December 2013

Accepted 16 February 2014

Available online 21 February 2014

\begin{abstract}
A B S T R A C T
A UMo powellite glass-ceramic designed by French workers to immobilise Mo-rich intermediate-level waste was found to be quite leach resistant in water at $90^{\circ} \mathrm{C}$ with the dissolution of $\mathrm{Cs}, \mathrm{Mo}, \mathrm{Na}, \mathrm{B}$ and Ca not exceeding $2 \mathrm{~g} / \mathrm{L}$ in normalised PCT tests. ${ }^{133} \mathrm{Cs}$ solid state nuclear magnetic resonance and scanning electron microscopy (SEM) showed the Cs to inhabit the glass phase. The microstructures were not greatly affected by cooling rates between 1 and $5^{\circ} \mathrm{C} /$ min or by introducing 10 times as much Cs and Sr. Protracted leach tests at $90^{\circ} \mathrm{C}$ showed surface alteration as evidenced by SEM and particularly transmission electron microscopy; the main alteration phase was a $\mathrm{Zn}$ aluminosilicate but several other alteration phases were evident. Voidage in the alteration layers was indicated from enhanced lifetimes in positron annihilation lifetime spectroscopy.
\end{abstract}

Crown Copyright $\odot 2014$ Published by Elsevier B.V. All rights reserved.

\section{Introduction}

Waste from reprocessed UMo nuclear fuel is rich in Mo, so a new UMo glass-ceramic formulation was devised by CEA scientists to accommodate $\sim 10 \mathrm{wt} \%$ of Mo [1,2] as well as a few percent of fission products. The short-term leachability as measured by Soxhlet testing is $\sim 3 \mathrm{~g} / \mathrm{m}^{2} /$ day [3]. PCT-type testing at $90{ }^{\circ} \mathrm{C}$ using a glass surface area-water volume ratio of $80 \mathrm{~cm}^{-1}$ gave a $B$ leach rate of $2.5 \times 10^{-6} \mathrm{~g} / \mathrm{cm}^{-2} /$ day over the 91-120 day leach period [3]. However since when Mo is present, Cs in glasses can sometimes form water-soluble Cs molybdate, we have focussed on the disposition of Cs by solid state nuclear magnetic resonance and scanning electron microscopy and the leachability of Cs in the UMo glass-ceramic.

Leaching in deionised water at $90{ }^{\circ} \mathrm{C}$ was studied by elemental extraction in PCT tests [4] and surface alteration methods. These latter methods included glancing angle X-ray diffraction, scanning and transmission electron microscopy and positron annihilation lifetime spectroscopy. The resistance to leaching offered by alteration layers will depend partly on their porosity. Positrons injected into dense solids typically have lifetimes of $0.1-0.2$ ns before they annihilate with electrons, but the presence of nanovoids

\footnotetext{
* Corresponding author. Tel.: +61 29717 3019; fax: +61 297179225 .

E-mail address: erv@ansto.gov.au (E.R. Vance).
}

gives rise to longer lifetimes because of the reduced electron density in such voids.

\section{Experimental}

The UMo glass-ceramic composition employed was (wt\%): $\mathrm{Na}_{2} \mathrm{O}$ (9.3); $\mathrm{B}_{2} \mathrm{O}_{3}$ (14.2); $\mathrm{Al}_{2} \mathrm{O}_{3}$ (7.0); $\mathrm{MoO}_{3}$ (9.9); $\mathrm{P}_{2} \mathrm{O}_{5}$ (3.0); $\mathrm{ZnO}$ (5.9); $\mathrm{ZrO}_{2}$ (3.3); $\mathrm{CaO}$ (6.1); $\mathrm{Cs}_{2} \mathrm{O}$ (0.3); $\mathrm{SrO}(0.4) ; \mathrm{Nd}_{2} \mathrm{O}_{3}$ (1.7); $\mathrm{SiO}_{2}$ (38.9). This was very similar to an earlier French composition [1]. $\mathrm{Na}, \mathrm{Al}, \mathrm{Zn}, \mathrm{Ca}, \mathrm{Cs}, \mathrm{Sr}$, and $\mathrm{Nd}$ nitrates were dissolved in water, the $\mathrm{P}$ was added as $\left(\mathrm{NH}_{4}\right)_{2} \mathrm{HPO}_{4}$, the Mo, $\mathrm{Zr}$ and B as dry metal oxides and the Si was added as Ludox, a $50 \mathrm{wt} \%$ aqueous colloidal solution. The mixture was stir-dried and calcined in air at $750{ }^{\circ} \mathrm{C}$ for $1 \mathrm{~h}$ before $\sim 15 \mathrm{~g}$ samples were melted in Pt crucibles at $1280^{\circ} \mathrm{C}$ for $1 \mathrm{~h}$ using thermal ramp rates of $5^{\circ} \mathrm{C} / \mathrm{min}$ for heating and $5^{\circ} \mathrm{C} / \mathrm{min}$ or $1^{\circ} \mathrm{C} / \mathrm{min}$ cooling rates. Sample density was determined to be $2.71 \mathrm{~g} / \mathrm{cm}^{3}$ using Archimedes' method in distilled water.

X-ray diffraction patterns were measured using a Philips PW1050 diffractometer (PANalytical Ltd., Almelo, Netherlands) with $\mathrm{Cu} \mathrm{K} \alpha$ radiation. Grazing incidence X-ray diffraction (GI XRD) measurements were performed using a BRUKER D8 Advance diffractometer, utilizing $\mathrm{Cu} \mathrm{K} \alpha$ radiation and a SOL-XE energy dispersive detector with a step size of $0.03^{\circ}$ and a counting time of $20 \mathrm{~s}$ per step. The diffractometer was fitted with an incident beam Gobël mirror and 0.18 parallel-plate collimator for parallel beam 
conditions. The incident angle was set at 1,2 or $3^{\circ}$ to achieve a maximum extinction of X-rays between $1-3 \mu \mathrm{m}$ from the surface. Scanning electron microscopy was carried out with a Zeiss Ultra Plus instrument operating at $15 \mathrm{kV}$ and equipped with an Oxford Instruments X-Max $80 \mathrm{~mm}^{2}$ SDD X-ray microanalysis system for semi-quantitative phase-composition analysis. Samples were mounted in epoxy resin and polished to a $1 \mu \mathrm{m}$ diamond finish. A $\sim 5 \mathrm{~nm}$ thick carbon film was deposited on the surface to remove charging effects.

High-resolution solid-state NMR experiments were carried out on a 9.4 T Varian Infinity (CMX) spectrometer operating at a Larmor frequency of $52.48 \mathrm{MHz}$ for ${ }^{133} \mathrm{Cs}$. Samples were packed in $4 \mathrm{~mm}$ zirconia rotors and spun at $15 \mathrm{kHz}$. The crystalline spectra were acquired with a simple Bloch decay $(\pi / 18)$ with a pulse repetition rate of $200 \mathrm{~s}$, which were non-saturating conditions and the glasses with $\pi / 2$ solid-echo with an exorcycle phase scheme. The time domain data were zero-filled to $t=0$ before Fourier transformation to eliminate any phase distortion of spinning sidebands. Spectra were referenced to aqueous $1 \mathrm{M} \mathrm{CsCl}$ via a secondary reference to solid $\mathrm{CsCl}$.

Transmission electron microscopy (TEM) was performed using a JEOL JEM 2010F (JEOL, Japan) equipped with a field emission gun (FEG) electron source operated at $200 \mathrm{kV}$. The TEM was equipped with an energy dispersive X-ray (EDX) spectrometer and NORAN System SIX microanalysis system (Thermo Electron Corporation, USA). The TEM specimen was prepared by lightly scraping the surface of the leached monolith to remove some of the leach product which was then lightly ground under ethanol and a few drops of the suspension deposited onto a holey carbon coated copper TEM grid.

7-day leaching experiments at $90{ }^{\circ} \mathrm{C}$ were conducted in triplicate on PCT powder samples. A hand ground sample of the glass ceramic was passed through a $150 \mu \mathrm{m}$ mesh sieve, followed by a $75 \mu \mathrm{m}$ mesh sieve. The $75-150 \mu \mathrm{m}$ glass ceramic powder was ultrasonically cleaned 3 times in cyclohexane, at 5 min intervals, to remove adhering fines. The cleaned sample was placed in an oven at $90{ }^{\circ} \mathrm{C}$ to dry then cooled to room temperature.

All tests were carried out in triplicate in clean Teflon vessels. Parallel blank tests, in duplicate, were also carried out to provide background levels of constituent elements. To each sample, ASTM Type 1 water was added at the ratio of $10 \mathrm{~mL}$ per $1 \mathrm{~g}$ of sample mass. The $\mathrm{pH}$ and temperature of the ASTM Type 1 water were measured using a calibrated Metrohm $713 \mathrm{pH}$ meter. The set of samples, including the blanks, was placed immediately into a calibrated, preheated oven at $90{ }^{\circ} \mathrm{C}$ and leached for 7 days.

After 7 days of leaching the samples were removed from the oven. As soon as the leachate had cooled to ambient temperature the vessels were reweighed and the sample filtered. Using a $0.45 \mu \mathrm{m}$ Sartorius Minisart filter attached to a $20 \mathrm{~mL}$ Terumo syringe, the filtered leachates were poured into clean, pre-weighed, labelled $25 \mathrm{~mL}$ polyethylene containers. A $5 \mathrm{~mL}$ aliquot of leachate was transferred into a clean labelled $25 \mathrm{~mL}$ polyethylene container for the $\mathrm{pH}$ measurement. The $\mathrm{pH}$ and temperature of the aliquot were measured using a calibrated Metrohm $713 \mathrm{pH}$ meter. The leachates were acidified with $\operatorname{Tracepur}^{\circledR} \mathrm{HNO}_{3}$ equal to $3 \%$ of the leachate volume. The acidified leachates and blanks were submitted for ICP-MS and ICP-OES analysis to quantify the cations present in each leachate.

The leachates were analysed for Mo and Cs using a Varian 820-MS system equipped with nickel cones, Micromist low flow nebuliser, double-glass Scott spray chamber, and SPS3 autosampler. The leachate was analysed for $\mathrm{Na}, \mathrm{Ca}$, and $\mathrm{B}$ using a Perkin Elmer Optima 5300DV ICP-OES system equipped a Ryton, double-pass Scott-type spray chamber, a GemTip Cross-Flow pneumatic nebuliser and a CETACC520 autosampler.
More extended leach tests were conducted on groups of three $6 \times 6 \times 2 \mathrm{~mm}$ plates of material which were polished to a $1 \mu \mathrm{m}$ diamond finish on one large face and were all immersed in $100 \mathrm{~mL}$ of deionised water at $90^{\circ} \mathrm{C}$ for various times and then individual plates were studied by glancing incidence X-ray diffraction, scanning electron microscopy or positron annihilation lifetime spectroscopy. Solution analysis was carried out as above. X-ray fluorescence data were obtained on a Rigaku WDXRF "Primus II" spectrometer with a Rh tube, using pressed pellets of powdered glass-ceramics and analysed with a semi-quantitative standardless SQX program.

Positron annihilation lifetime spectroscopy on leached glassceramic surfaces was mainly studied using the beamline [5] at the Australian National University in which pulsed positrons having energies of $1-20 \mathrm{keV}$ and ranges in the solids of up to $\sim 1 \mu \mathrm{m}$ can be utilised. Positrons injected into dense solids typically have lifetimes of 0.1-0.2 nsec when they annihilate with electrons, but the presence of nanovoids gives rise to longer lifetimes, as positrons become trapped in the voids where there is a near absence of electrons. The apparatus utilises a ${ }^{22} \mathrm{Na}$ source moderated by solid Ne combined with a Surko trap to produce a pulsed beam of variable energy positrons, $5 \mathrm{keV}$ in the present case, giving a mean penetration depth of approximately $200 \mathrm{~nm}$. Annihilation gammas are detected after injection into the sample using a $\mathrm{BaF}_{2}$ crystal combined with a fast photomultiplier tube. The pulses typically have $\sim 800$ ps full width at half maximum (FWHM). The shortest lifetime able to be confidently resolved by the positron beam is $\sim 0.3 \mathrm{~ns}$ after an accumulation of 1.5 million counts.

A benchtop PALS setup was also employed to study the bulk properties of the glass-ceramics, with sandwiches of solids $\sim 10 \mathrm{~mm}$ square or in diameter and about $3 \mathrm{~mm}$ thick, with the large faces adjacent to the positron source polished to a $1 \mu \mathrm{m}$ diamond finish. The arrangement of an $8 \mu \mathrm{m}$ thick kapton sandwich containing $\sim 30 \mu \mathrm{Ci}$ of ${ }^{22} \mathrm{NaCl}$ as described by Guagliardo et al. [6] using similar electronic gamma detection was used to obtain the PALS spectrum of the unleached solids, to assist defining the beamline PALS results as representative of the alteration layers or the bulk material. Here over $10^{6}$ counts were accumulated and measurements were conducted at room temperature and in air. The spectra were deconvoluted using PALSFIT Version 1-64 software [7] to obtain the various lifetime components. The average experimental errors are of the order of 2 ps for the lifetime results and $<1 \%$ for the intensities.

\section{Results and discussion}

While Schuller et al. [2] concentrated on phase separation phenomena in similar glass-ceramics which were quenched from the melt, our focus is a material poured from the melt into canisters. Such material would have cooled relatively slowly and $5^{\circ} \mathrm{C} / \mathrm{min}$ is doubtless an overestimate of the cooling rate, but will be a lot more realistic than quenching. The materials were partly translucent and X-ray diffraction (Fig. 1) showed the principal crystalline species present was $\mathrm{CaMoO}_{4}$ (JCPDS card 29-351), with a minor apatite phase containing Nd (JPCDS card 32-175), plus a glassy phase giving rise to a diffuse hump centred at around $25^{\circ}$ in $2 \theta$.

SEM results for this glass are shown in Fig. 2(a) and (b), in which the samples were cooled from the melt at 5 and $1{ }^{\circ} \mathrm{C} / \mathrm{min}$ respectively. As found by previous workers [2] the phase-separated regions constitute around $15 \%$ of the sample volume. The white regions in the phase separated globules are basically $\mathrm{CaMoO}_{4}$ containing the $\mathrm{Sr}$, some of the $\mathrm{Zn}$ and most of the Nd presumably substituting for $\mathrm{Ca}$, plus a small amount of glass; the grey regions of the globules are apatites containing $\mathrm{Zn}$ and $\mathrm{Nd}$; and the 


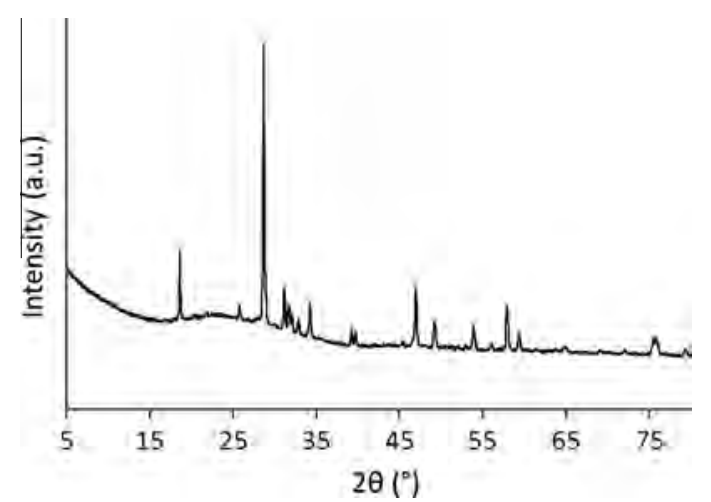

Fig. 1. XRD pattern from UMo glass-ceramic. Diffuse peak between $\sim 15$ and $40^{\circ}$ of $2 \theta$ due to glass. The main peaks derive from powellite, $\mathrm{CaMoO}_{4}$ (JCPDS29-351)
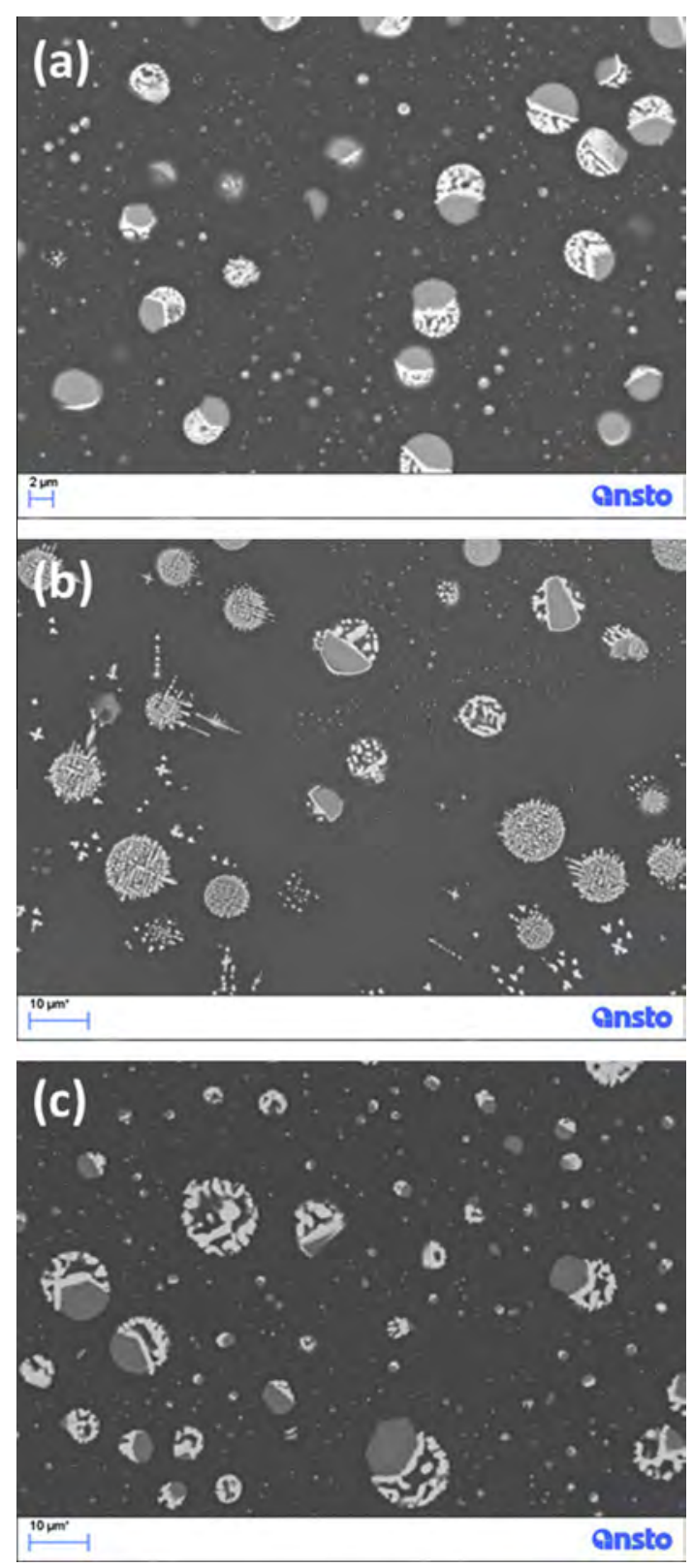

Fig. 2. Backscattered SEM of UMo glass-ceramic cooled from the melt at (a) $5^{\circ} \mathrm{C} /$ min and (b) $1{ }^{\circ} \mathrm{C} / \mathrm{min}$ and (c) the glass-ceramic containing 10 times more $\mathrm{Cs}$ and $\mathrm{Sr}$, cooled at $5^{\circ} \mathrm{C} /$ min from the melt. aluminosilicate glass matrix is devoid of phosphate, but contains around $20 \%$ of the Mo. XRF results confirmed the final composition of the glass-ceramics was very close to the starting stoichiometry.

XRF showed the composition of the glass-ceramic cooled at $1^{\circ} \mathrm{C} / \mathrm{min}$ was essentially unaltered by the change of heat treatment, apart possibly from a small loss of Na because of the extended time above the melting point. XRD gave similar results to that for the material cooled at $5^{\circ} \mathrm{C} / \mathrm{min}$. The phase separation details were slightly altered insofar as the globules exhibited a finer structure (see Fig. 2(b)) and the glass composition was basically the same. In another sample in which the contents of $\mathrm{Cs}$ and $\mathrm{Sr}$ were increased to 10 times that of the above material, the phase separation structure was substantially unaltered (Fig. 2(c)).

\section{1. ${ }^{133}$ CS MASNMR spectroscopy}

The ${ }^{133}$ Cs MASNMR spectra can give an element specific view of the location of Cs in the phase separated UMo glass-ceramic in either crystalline or glassy fractions. Central transition ${ }^{133} \mathrm{Cs}$ MASNMR spectra in well-ordered crystalline Cs aluminosilicate phases have shown quite narrow resonance lines [8] due to the low nuclear quadrupole moment of the ${ }^{133} \mathrm{Cs}$ nucleus $\left(-3.4 \times 10^{-31} \mathrm{~m}^{2}\right)$ and the absence of broadening of the central $\left( \pm m_{I}=1 / 2\right.$ transition), by the first order quadrupole effect. The spectrum shown in Fig. 3(a) is of pure caesium molybdate $\left(\mathrm{Cs}_{2} \mathrm{MoO}_{4}\right)$. In addition to narrow lines this crystalline sample also exhibits a long spin-lattice relaxation time and requires long acquisition times. The spectrum shown in Fig. 3(b) was acquired with an echo, but with relaxation characteristics that would allow the observation of Cs in a crystalline phase. The large ${ }^{133} \mathrm{Cs}$ line width of the UMo glass spectrum is attributed to a wide distribution of chemical shifts resulting from a distribution of bond-lengths and angles typical of a glass. In Fig. 3(c) the ${ }^{133} \mathrm{Cs}$ MASNMR spectrum of the widely known SON68 surrogate glass for the R7T7 nuclear waste glass is shown for comparison and shows a similar spectral response.

\subsection{Durability assessment}

PCT results at $90^{\circ} \mathrm{C}$ for the glass-ceramics cooled from the melt at $1^{\circ} \mathrm{C}$ and $5{ }^{\circ} \mathrm{C} / \mathrm{min}$ are shown in Table 1 . Although they showed higher leach rates for $\mathrm{Ca}$ and Mo for the $5^{\circ} \mathrm{C} / \mathrm{min}$ cooling rate, as

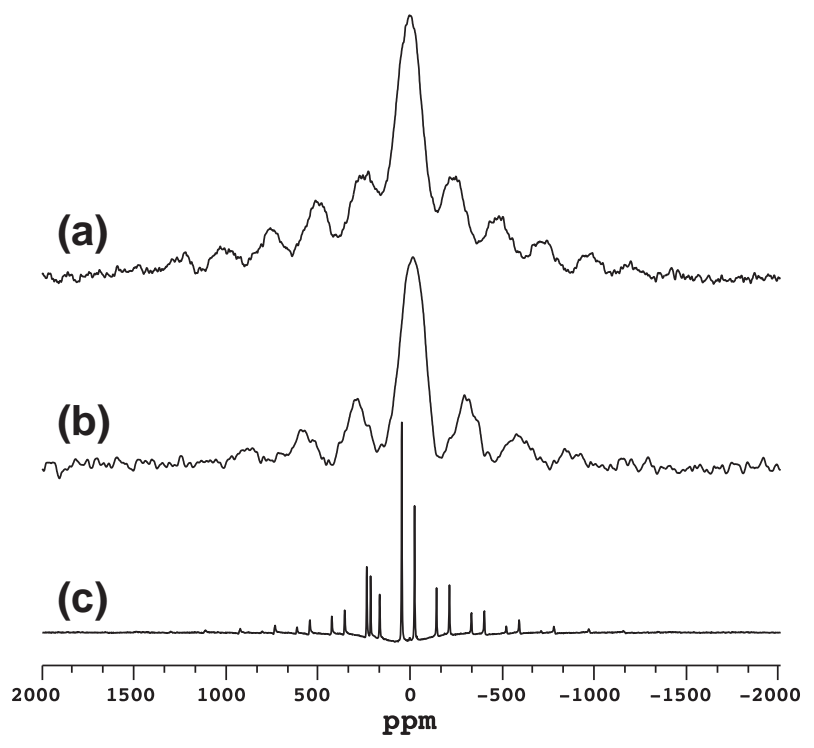

Fig. 3. ${ }^{133} \mathrm{Cs}$ MAS NMR spectra of (c) crystalline $\mathrm{Cs}_{2} \mathrm{MoO}_{4}, 16$ scans (Bloch decays) $\pi / 18$ pulses with $1000 \mathrm{~s}$ delay; (b) UMo glass obtained with 287 scans (echoes) and 200 s delay spun at $15 \mathrm{kHz}$; (a) SON68 glass, obtained with 105000 scans (echoes) with $0.5 \mathrm{~s}$ delay spun at $13 \mathrm{kHz}$. 
Table 1

Normalised PCT results for various elements in glass-ceramic cooled from the melt at nominal rates of 1 and $5{ }^{\circ} \mathrm{C} / \mathrm{min}$.

\begin{tabular}{lll}
\hline Element $(\mathrm{g} / \mathrm{L})$ & Cooling rate $\left({ }^{\circ} \mathrm{C} / \mathrm{min}\right)$ & \\
\cline { 2 - 3 } & 1 & 5 \\
\hline $\mathrm{Na}$ & 1.9 & 1.7 \\
$\mathrm{~B}$ & 2.0 & 1.2 \\
$\mathrm{Cs}$ & 0.3 & 0.4 \\
$\mathrm{Mo}$ & 0.7 & 1.2 \\
$\mathrm{Ca}$ & 0.03 & 0.6 \\
\hline
\end{tabular}

against the $1{ }^{\circ} \mathrm{C} / \mathrm{min}$ cooling rate, all measured values were reasonably low, $<0.2 \mathrm{~g} / \mathrm{m}^{2} / \mathrm{d}$.

$6 \times 6 \times 2 \mathrm{~mm}$-sized plates of glass-ceramic, polished down to $1 \mu \mathrm{m}$ diamond on one side, were leached in a large volume of water for 1 or 3 months. The derived $\mathrm{Na}, \mathrm{B}, \mathrm{Si}, \mathrm{Cs}$, Mo, and $\mathrm{Al}$ normalised leach rates of the sample cooled from the melt at $5{ }^{\circ} \mathrm{C} / \mathrm{min}$ for 90 days' exposure all corresponded to $0.2 \mathrm{~g} \mathrm{~m}^{-2}$ day $^{-1}$ within a factor of two.

Although there were visual indications of a thin alteration layer after leaching, no crystalline alteration phases were observed from glancing angle XRD. SEM showed evidence of the alteration layer insofar as the images appeared blurred, but chemical information on its nature could not be obtained.

From TEM, a sheet like $\mathrm{Zn}-\mathrm{Al}-\mathrm{Si}-\mathrm{O}$ phase formed the bulk of material collected from the leached sample (Fig. 4(a)). Selected area electron diffraction (SAED) shows a fine-grained polycrystalline structure (Fig. 4(b)). A very fine-grained $\mathrm{Zr}-\mathrm{Si}-\mathrm{Al}-\mathrm{O}$ phase was also common (Fig. 5(a)) which selected area electron diffraction showed to be amorphous (Fig. 5(b)). Several minor
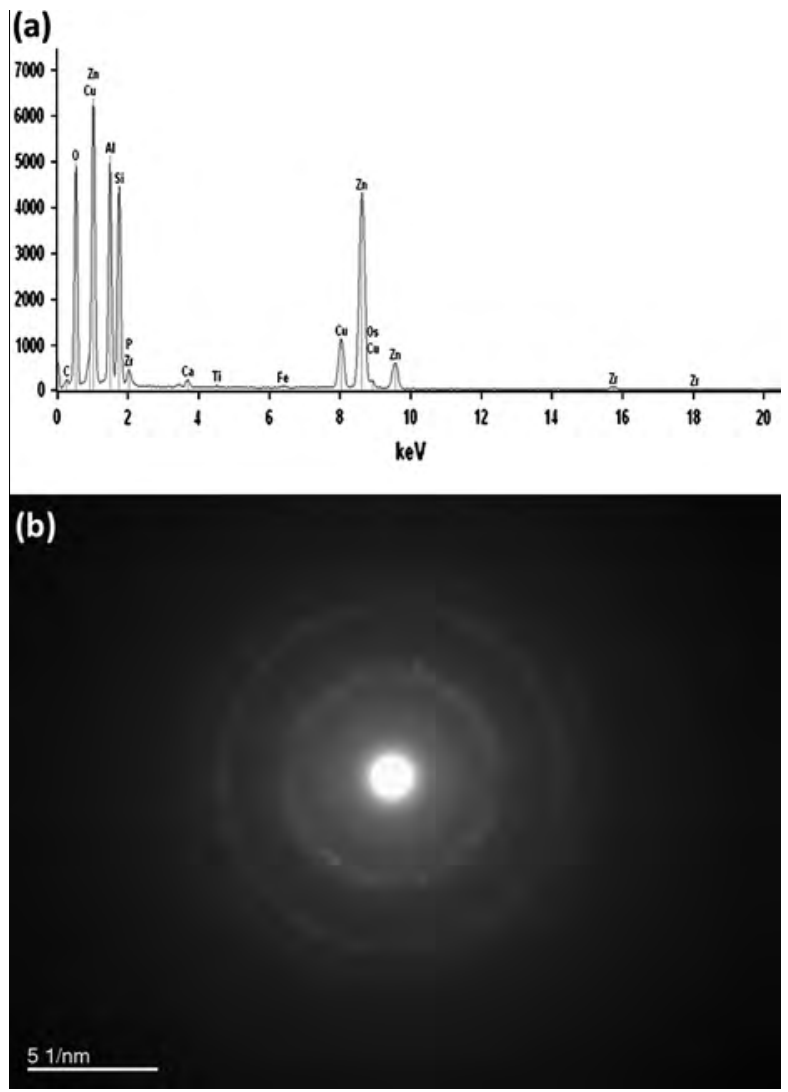

Fig. 4. (a) Elemental analysis using TEM-EDS and (b) SAED for the $\mathrm{Zn}-\mathrm{Al}-\mathrm{Si}-\mathrm{O}$ phase.
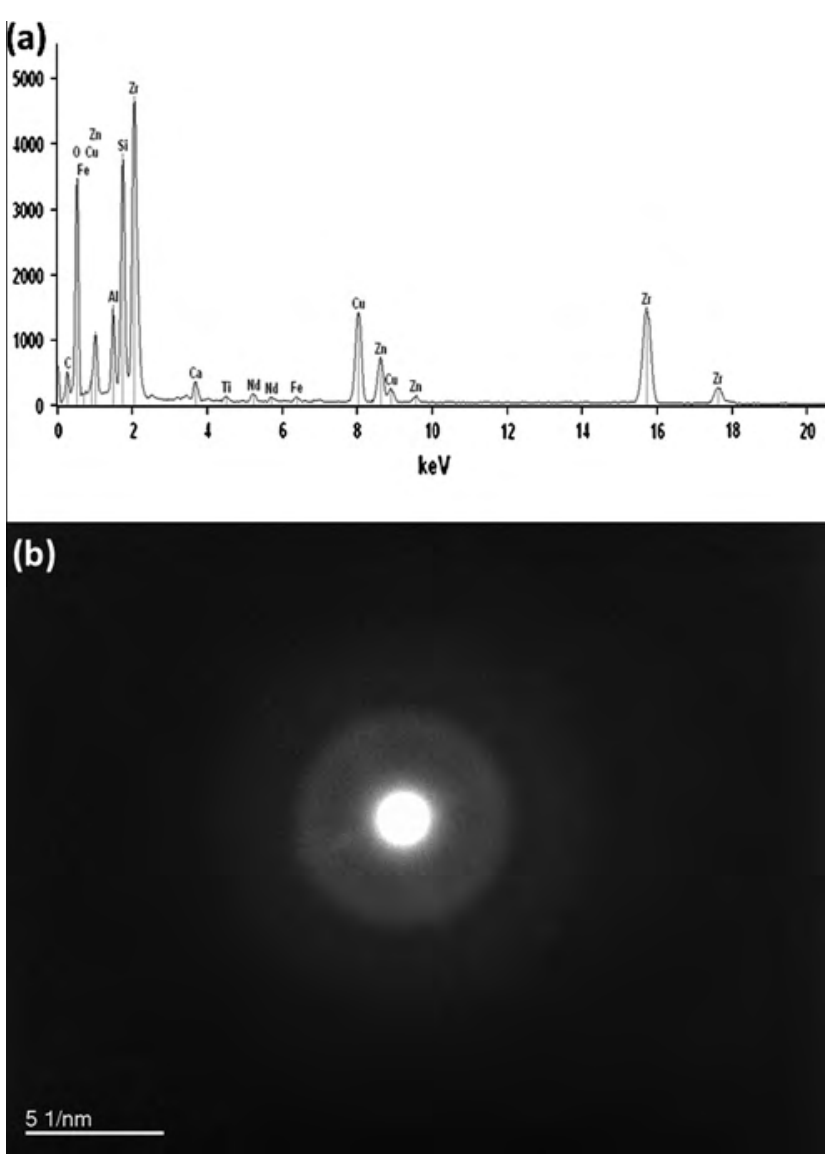

Fig. 5. (a) Elemental analysis using TEM-EDS and (b) SAED for the $\mathrm{Zr}-\mathrm{Si}-\mathrm{Al}-\mathrm{O}$ phase.

$\mathrm{Zr}-\mathrm{Nd}-\mathrm{Zn}-\mathrm{Ca}-\mathrm{P}-\mathrm{O}$ crystalline phases with different morphology were also present in the alteration products. Examples of these are shown in Fig. 6.

\subsection{PALS measurements}

To our knowledge, no previous PALS work has been carried out on nuclear waste glasses or glass-ceramics and we are starting such work at ANSTO. PALS measurements of the bulk properties of the unleached glass-ceramic cooled at $5{ }^{\circ} \mathrm{C} / \mathrm{min}$ from the melt gave a main $(\sim 80 \%)$ lifetime at $0.35 \mathrm{~ns}$ and a minor $(\sim 20 \%)$ lifetime component at $0.87 \mathrm{~ns}$, using the benchtop equipment. Results from the beam-based PALS on the leached surface of the glass-ceramic for a range of leaching times are given in Table 2. The results for the unleached sample were somewhat different to that from the benchtop measurements, particularly in regard to the intensity and lifetime of the minor second lifetime component. This is perhaps due to the enhanced surface sensitivity of the beam experiment, and may be due to polishing strains. Note that the intensities from the beam-based data do not add to $100 \%$ as only lifetimes that are different from those present in a reference sample are reported. For the 43 day leached sample, we see an increase in the shortest lifetime observed, along with lifetimes of 6 and $66 \mathrm{~ns}$, corresponding to pore radii of 0.5 and $5 \mathrm{~nm}$ respectively, using the extended Tau-Eldrup model [9]. The shorter lifetimes observed in the measurements are not so easily related to pore sizes, and probably correspond to vacancy clusters of a few atoms within the alteration layers, with increasing lifetimes indicating increasing size. In the case of the 90 day leached sample, the shortest 

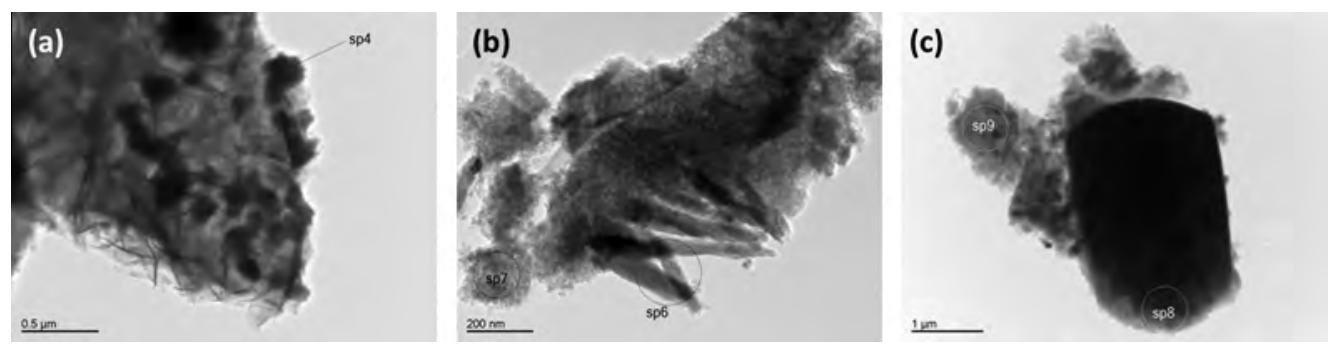

Fig. 6. TEM images for various minor $\mathrm{Zr}-\mathrm{Nd}-\mathrm{Zn}-\mathrm{Ca}-\mathrm{P}-\mathrm{O}$ crystalline phases.

Table 2

Beamline positron lifetimes for $90^{\circ} \mathrm{C}$ leached glass-ceramic cooled from the melt at $5^{\circ} \mathrm{C} / \mathrm{min}$.

\begin{tabular}{llllllll}
\hline Time (days) & $\tau_{1}(\mathrm{~ns})$ & $I_{1}(\%)$ & $r_{1}(\mathrm{~nm})$ & $\tau_{2}(\mathrm{~ns})$ & $I_{2}(\%)$ & $r_{2}(\mathrm{~nm})$ & $\tau_{3}(\mathrm{~ns})$ \\
\hline 0 & 0.34 & 41 & & 1 & 4 & & \\
43 & 0.56 & 28 & 6 & 5 & 0.5 & \\
90 & 0.76 & 25 & 39 & 1.5 & 1.2 & 86 \\
\hline
\end{tabular}

lifetime component increases again, and a single long lifetime of $39 \mathrm{~ns}$ is observed, corresponding to a pore radius of $1.2 \mathrm{~nm}$.

It would seem that as the more leachable ions are removed from the glass, they leave behind vacancy clusters of increasing size, corresponding to the short lifetime components observed. The longer lifetime components indicate the formation of openvolume defects in the surface alteration layer(s) of the glass. Over time, the size of these channels or voids can change and the reduced intensity component of the long lifetime observed in the 90 day leached sample indicates that these defects may even be closing over time, as the alteration layer as a whole thickens.

\section{Conclusions}

The phase separation details in the French UMo powellite glassceramic were only slightly affected using different cooling rates of a few ${ }^{\circ} \mathrm{C} / \mathrm{min}$ and canisterised material produced from melts should be appropriately leach resistant at $90^{\circ} \mathrm{C}$ insofar as the normalised leaching of all elements studied did not exceed $2 \mathrm{~g} / \mathrm{L}$ in a 7 -day PCT test. The 90 day leach rates in more dilute aqueous solutions were around $0.2 \mathrm{~g} \mathrm{~m}^{-2}$ day. All the Cs appears to be in the glass phase as shown by NMR and SEM and the $\mathrm{Sr}$ is in solid solution with the $\mathrm{CaMoO}_{4}$ phase. Extended leaching at $90{ }^{\circ} \mathrm{C}$ gave rise to a variety of alteration phases as observed by transmission electron microscopy and indications in positron annihilation lifetime beam spectroscopy of open volume defects such as voids or channels in the altered layer. It is of course recognised that drying and evacuation could have some effects on the overall porosity of the alteration layers.

\section{Acknowledgements}

We thank the Australian Research Council for funding support of the PALS work under the CAMS program, A. Altantsetseg for the X-ray fluorescence measurements, and C. Jennison, K. Lu and I. Watson for assistance with sample preparation.

\section{References}

[1] O. Pinet, J.F. Hollebecque, F. Angeli, P. Gruber, S. Naline, Vitrification of Molybdenum-Rich High-Level Solutions by the Cold Crucible Melter Process11502, WM2011 Conference, March 3, 2011, Phoenix, AZ, USA

[2] S. Schuller, O. Pinet, B. Penelon, J. Amer. Ceram. Soc. 94 (2011) 447-454.

[3] R. Do Quang, V. Petitjean, F. Hollebecque, O. Pinet, T. Flament, A. Prod'homme, Vitrification of HLW produced by Uranium/Molybdenum Fuel Reprocessing in Cogema's Cold Crucible Melter, WM'03 Conference, Tucson, AZ, USA, 2003.

[4] Standard Test Methods for Determining Chemical Durability of Nuclear, Hazardous, and Mixed Waste Glasses and Multiphase Glass Ceramics: The Product Consistency Test, ASTM Committee C26, 2000.

[5] J.P. Sullivan, J. Roberts, R.W. Weed, M.R. Went, D.S. Newman, S.J. Buckman, Meas. Sci. Technol. 21 (2010) 085702.

[6] P. Guagliardo, E.R. Vance, G.R. Lumpkin, M.G. Blackford, K. Sudarshan, J. Davis, S. Samarin, J.F. Williams, J. Amer. Ceram. Soc. 96 (2013) 3286-3289.

[7] J.V. Olsen, P. Kirkegaard, N.J. Pedersen, M. Eldrup, Phys. Status Solidi (c) 4 (2007) 4004-4006.

[8] S.E. Ashbrook, K.R. Whittle, L. Le Pollès, I. Farnan, J. Am. Ceram. Soc. 88 (2005) $1575-1583$.

[9] T.L. Dull, W.E. Frieze, D.W. Gidley, J.N. Sun, A.F. Yee, J. Phys. Chem. B 105 (2001) 4657-4662. 